\title{
El impacto de Humboldt en la Botánica y Fitogeografía del Ecuador
}

\author{
Katya Romoleroux \\ Escuela de Ciencias Biológicas, Pontificia Universidad Católica del Ecuador \\ KROMOLEROUX@puce.edu.ec
}

\section{Breve reseña sobre el viaje de Humboldt a América}

Alexander von Humboldt nace en Berlín en 1769 de una familia rica y noble, su padre muere cuando aún es niño. En 1790, inicia sus estudios en economía en Göttingen; sin embargo, su interés fue siempre las ciencias naturales y termina especializándose en estas áreas. En 1796, mientras es director de una industria minera en Freiberg, su madre muere dejando una herencia apreciable, la cual Humboldt posteriormente usa para la gran expedición científica que había planificado a América.

En 1799, inicia su viaje a América en compañía del botánico francés Aimé de Bonpland, reciben un permiso especial del rey de España para ser recibidos en las colonias españolas. Desde 1799 hasta 1804 visitan los actuales países de Venezuela, Cuba, Colombia, Ecuador, Perú, México, Estados Unidos, y el 9 de julio de 1804 regresan desde Filadelfia hasta Francia (Nelken, 1980).

\section{Estadía de Humboldt y Bonpland en el Ecuador}

A fines de diciembre de 1801, Humboldt y Bonpland llegan al Ecuador, atraviesan Carchi e Imbabura y llegan a Quito en enero de 1802, su anfitrión fue Juan Pío Montúfar, su estadía en Quito se prolonga hasta julio de 1802. Durante este período los dos científicos ascendieron al Antisana, al Pichincha y posteriormente al Chimborazo, considerado en ese entonces el volcán más alto del mundo; otras montañas visitadas por ellos fueron Cotacachi, Imbabura, Cayambe, Pasochoa, Atacazo, Corazón, Rumiñahui e Iliniza. Luego viajan al sur del Ecuador, en compañía de Carlos Montúfar, ascendieron el Cotopaxi y visitaron varias localidades pasando por Cuenca y Loja donde visitan y estudian los bosques de Cinchona, planta conocida como remedio para curar la malaria; visitan además Zaruma, Gonzanamá hasta Macará. En agosto de 1802, dejan el Ecuador y se dirigen al Perú, posteriormente el 9 de enero de 1803 regresan a Guayaquil, donde se reúnen con Juan Tafalla, botá- 
nico español, y visitan Samborondón. Durante su estadía en el Ecuador recorren un total de 169 localidades, en la mayoría de éstas, Humboldt y Bonpland, hacen colecciones de plantas y de otros organismos, además de valiosas observaciones y gráficos que serán esenciales para el progreso de la botánica y la fitogeografía (Sandwith, 1926).

\section{Resultados científicos del viaje Humboldt a América}

\section{Colecciones de plantas:}

Se colectaron más de 25000 especímenes de plantas, además de datos climatológicos, geográficos y ecológicos

Las colecciones se hicieron por triplicado y fueron enviadas a París en tres diferentes barcos para evitar perdidas, todas llegaron.

Entre los años 1805-1825 Humboldt, Bonpland y Kunth, botánico alemán discípulo de Willdenow, trabajaron arduamente en la catalogación, identificación y descripción en estas muestras.

\section{Descripciones de plantas:}

Se realizan descripciones de 7000 diferentes especies de plantas incluyendo 4000 nuevas especies para la ciencia. De estas descripciones 5500 fueron angiospermas (plantas con flores), de éstas 3000 eran enteramente nuevas (Humboldt, 1807).

La diversidad de las plantas conocidas en el mundo aumentó de 10000 a
14000 especies, ningún otro viaje había añadido tantas nuevas especies de plantas.

Muchas de las especies descritas por Humboldt, Bonpland y Kunth fueron anteriormente descritas e ilustradas por el botánico español radicado en Colombia José Celestino Mutis (17701806); sin embargo, los datos de Mutis no llegaron a publicarse sino mucho después que los de Humboldt.

Una de las publicaciones más completas con las descripciones de las plantas colectadas es la obra en siete tomos: "Nova Genera et Species Plantarum" descritas por Kunth, Bonpland y Humboldt (1815-1825).

Aporte de las colecciones realizadas por Humboldt y Bonpland para la botánica del Ecuador

Humboldt y Bonpland fueron los primeros botánicos que hicieron una colección importante de plantas ecuatorianas que fue transportada exitosamente a Europa. Sus colecciones fueron depositadas en los principales herbarios de esa época París y Berlín y fueron la base para la publicación de muchos nuevos taxones ecuatorianos.

En la publicación en dos tomos de "Plantes Équinoxiales" (Humboldt y Bonpland 1808, 1809), describen por primera vez varias plantas americanas y más de 20 nuevas especies ecuatorianas con sus respectivas ilustraciones. Algunas de ellas muy útiles como es el caso de Andromachia igniaria, cuya 
corteza era utilizada para encender leña (Suplemento Ministerial, 2009); en Loja, Humboldt estudia las variedades de Cinchona o quinina, la planta curativa contra la malaria, descubre una variedad nueva y mejor a la que nombran Cinchona condaminea (Minguet, 1985). Aunque los duplicados de estas especies tipo enviados a Berlín fueron quemados durante la segunda guerra mundial, la mayoría de especies tipo se encuentran en la actualidad en el Herbario de París y algunos herbarios estadounidenses y otros europeos, ya que en muchos casos se hicieron más de tres duplicados. Actualmente, se cuenta con imágenes digitalizadas de muchas de ellas.

\section{Aporte del viaje de Humboldt para la Geografía de las Plantas y Ecología vegetal}

Después de del viaje de Humboldt y Bonpland y sus observaciones, prácticamente fundan el nuevo campo de la ciencia que es el estudio de la Fitogeografía o Geografía de la plantas en los trópicos. El concepto de Humboldt sobre geografía de las plantas fue bastante amplio e incluye distribución, ecología y biodiversidad, posteriormente se diferenciaron como disciplinas separadas.

Las dos principales publicaciones en las que Humboldt plasma sus estudios sobre la geografía de las plantas son:
1. "Ideas para una Geografía de las Plantas" (1807), más un Cuadro de la Naturaleza de los países tropicales, esta publicación contiene:

A. Descripciones de 17 diferentes formas de vida de las plantas; es decir, las adaptaciones ecológicas de las plantas, este fue el primer sistema de formas de vida vegetales propuesto.

B. Descripción de la relación entre clima, elevación y distribución de las plantas en los trópicos plasmado en su Cuadro de la Naturaleza, con el volcán Cotopaxi y el Chimborazo como modelos. La distribución altitudinal de los taxones vegetales fue correlacionada con 14 diferentes parámetros abióticos. Fue la primera descripción de cinturones altitudinales de vegetación de los Andes y de los trópicos.

2. "La distribución geográfica de las plantas en relación al clima y a la elevación" (1817), esta publicación contiene:

A. Análisis de la distribución mundial de la riqueza de especies, basados en las familias de plantas. Constituye el primer análisis de biodiversidad.

B. Comparación latitudinal de los cinturones altitudinales de vegetación, desde el ecuador hasta los polos, Humboldt demuestra que los cinturones altitudinales de vegetación, que incluyen las líneas de bosque, 
decrecen hacia las latitudes más altas. Los cambios latitudinales y de elevación en la vegetación son similares y correlacionados con los cambios climáticos (temperatura). Esta correlación entre temperatura y los cambios de latitudinales y altitudinales en la vegetación es llamada la Ley de Humboldt.

Se puede afirmar que Alexander von Humboldt fundó las ciencias de la Ecología vegetal y la Fitogeografía como resultado de sus viajes al Ecuador y otras regiones tropicales con Aimé de Bonpland durante 1799 y 1804 . Por lo tanto, con la llegada de Humboldt, hace 200 años, se iniciaron los estudios de vegetación en el Ecuador y fueron el puntal para varios botánicos que siguieron estudiando y publicando descripciones de la vegetación y de la Fitogeografía ecuatoriana.

\section{BIBLIOGRAFÍA}

Botting, D. 1973. Humboldt and the Cosmos. Prestel, Munich.

Humboldt F. W. H. A. von y A. Bonpland. 1808, 1809. Voyage de Humboldt et Bonpland. Plantes Equinocciales, vol. 1, 2. Tübingen u. Paris.

Humboldt, F. W. H. A. von y A. Bonpland. 1807. Ideen zur einer Geographie der Pflanzen nebst einen Naturalgemälde der Tropenländer. Tübingen u. Paris.
Humboldt, F. W. H. A. Von. 1817. La distribución geográfica de las plantas en relación al clima y a la elevación. Librariae Graeco Latino Germanico, Paris.

Kunth K. S., A. Bonpland y F. W. H. A. von Humboldt. 1915-1825. Nova Genera et Species Plantarum, vols. 1-7, Librariae Graeco Latino Germanico, Paris.

Minguet, C. 1985. Alejandro de Humboldt Historiador y Geógrafo de la América Española (1799-1804), vol. 1. Imprenta Universitaria, México.

Nelken, H. 1980. Alexander von Humboldt. Bildenisse und Künstler eine Dokumentierte Ikonographie, Berlin.

Sandwith, N. Y. 1926. Humboldt and Bonpland's itinerary in Ecuador and Peru. Kew Bulletin 181-190.

Suplemento Ministerial. 2009. Plantas Ecuatorianas Bicentenarias: Humboldt y Bonpland, contribución al conocimiento de la flora del Ecuador, Mayo 2009. Ministerio de Cultura, Quito, Ecuador. 